\title{
ESPIRITUALIDADE E SAÚDE: A EXPERIÊNCIA GREGA ARCAICA
}

\author{
SPIRITUALITY AND HEALTH:
}

THE ARCHAIC GREEK EXPERIENCE

FABRICIO POSSEBON ${ }^{(*)}$

\begin{abstract}
RESUMO
O estudo do vocabulário grego arcaico, apoiado em passagens dos textos épicos, nos permite construir um modelo de constituição do ser. O homem, ánthropos, seria então um ser pluridimensional, formado por diversos corpos ou envoltórios: o físico (sôma), o vital (pneûma), o emocional (thymós) e o mental (noûs). Os corpos abrigariam a essência, ou seja, a alma (psykhé). Nossa hipótese é que os sistemas modernos pluridimensionais têm como base o sistema grego, modernamente enriquecido com a contribuição do saber oriental. Espiritualidade é aqui entendida como a busca pela psykhé, caminho que passa pela harmonia dos envoltórios. O estado de desarmonia é a doença, e a saúde é o perfeito equilíbrio.
\end{abstract}

Palavras-Chave: Tradição Grega Arcaica. Espiritualidade e Saúde. Visão Holística.

\section{ABSTRACT}

The study of archaic Greek vocabulary, supported by passages of epic texts, allows us to build a model of constitution of being. The man, anthropos, then would be a multi-dimensional being, formed by various bodies or wraps: physical (soma), vital (pneuma), emotional (thymos) and mental (nous). The bodies would house the essence, that is, the soul (psykhe). Our hypothesis is that the multi-dimensional modern systems are based on the Greek system, modernly enriched with the contribution of eastern know. Spirituality is understood here as a search for psykhe; path that passes through harmony of the bodies. The disharmonic state is sickness and health is the perfect balance.

KEYWORDS: Archaic Greek Tradition. Spirituality and Health. Holistic Point of View.

INTRODUÇÃO

Propomos neste estudo investigar uma possível conceituação de espiritualidade e saúde, e a conexão entre ambas, na tradição grega arcaica. Partiremos do primeiro termo, uma vez que entendemos ser o segundo dependente da visão de constituição de ser, implicada no primeiro.

Espiritualidade é já um termo complexo formado a partir do vocábulo "espírito", a tradução portuguesa do latim spiritus. Este, por sua vez, é a tradução do grego pneûma ${ }^{1}$ que, segundo nossa visão, lhe dá o seu significado mais antigo. Nosso caminho é o seguinte: explorar o vocabulário grego arcaico

(*) Professor doutor do Programa de Pós-Graduação em Ciência das Religiões da Universidade Federal da Paraíba. E-mail: fabriciopossebon@gmail.com.

$1 \pi v \varepsilon \hat{v} \mu \alpha$. Daí derivam muitos termos, por exemplo, pneumonia, apneia, pneu (recorde-se o envoltório cheio de ar). Pulmão em grego é pneúmon = $\pi v \varepsilon v ́ \mu \omega \nu$. 
para, a partir dele, propor uma constituição do ser. Entendida essa constituição, definiremos saúde como harmonia entre suas partes constituintes, e doença como desarmonia entre elas.

O vocabulário dito arcaico é aquele usado, sobretudo, na épica de Hesíodo e Homero. São bastante fluidos e incertos os significados de muitos termos aqui analisados que, em épocas posteriores, procurarão ter definição mais precisa. Vai se tratar sempre de nossa escolha pessoal para a significação escolhida, a qual objetiva construir um sistema coerente e simultaneamente comparável com outras tradições. Portanto, nossa interpretação ficará restrita a uma visão do ser neste mundo antigo grego. Todavia há que se ter presente que toda a Grécia posterior se construiu a partir desses pressupostos e que a tradição latina é, grosso modo, uma reelaboração da grega, chegando assim até os tempos modernos. Embora as conclusões que pretendemos alcançar sejam para um local e data relativamente bem definidos, acreditamos numa quase validade universal, pelo menos para o ocidente, herdeiro da cultura greco-romana. Entendemos finalmente que os sistemas de tradições esotéricas e ocultistas têm por base este sistema grego arcaico, revitalizado nos tempos modernos pela chegada do saber oriental.

\section{CONSTITUIÇÃO DO SER}

O conceito de vida, bíos $^{2}$, parece ligar-se de modo mais imediato à ideia de respirar. Identifica-se que um indivíduo está vivo se ele está respirando, o que se verifica ainda hoje experimentalmente entre leigos com um vidro posto sob suas narinas. Assim, o complexo fenômeno vida se reduz em termos simples à respiração. Um corpo morto se distingue de um corpo vivo, porque este respira. Um corpo desacordado assim se distingue de um corpo morto, mas se distingue também de um corpo em estado de vigília, porque neste se manifesta alguma habilidade intelectual ou alguma expressão afetiva. Dessas constatações mais imediatas e concretas extraímos três elementos: há um corpo; este está vivo quando preenchido pelo ar respirado, há um sopro que lhe dá a vitalidade preenchendo-o; e há um elemento que é a individualidade do ser, aquele que

\footnotetext{
${ }^{2}$ Há dois termos gregos de difícil distinção: bíos (ßíos): a vida, isto é, a vida em si, a existência (BAILLY, p.

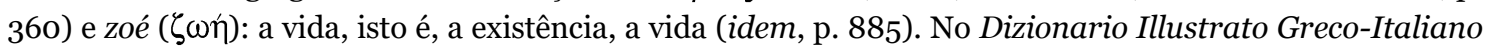
de H. G. Liddell e Robert Scott, edição sob os cuidados de Q. Cataudella, M. Manfredi e F. di Benedetto (p. 235): bíos: a vida, mas não vida material (zoé), se bem curso da vida ou gênero de vida [em latim vita] e zoé: o viver, meios para viver, substâncias; (depois de Homero): vida, existência (idem, p. 563).
} 
pensa, que sente e que age. A tradição grega usa respectivamente os termos sôma ${ }^{3}$, pneûma e psykhé para essas três ideias.

Sôma é o que vemos materialmente, com membros, órgãos, tecidos, ossos, etc.. Pneûma liga-se ao verbo pnéo (ou pneío): soprar, em seus múltiplos usos como soprar um instrumento, emanar um odor, o soprar dos ventos, respirar. Por outro lado, esse sopro se distingue do ar atmosférico, cujos termos são aér, atmós $^{4}$ (vapor, exalação), e do vento propriamente dito ánemos 5 . Isso parece significar que o ar no corpo já é outra coisa. Podemos extrair daí algumas interpretações, a saber: ou o ar atmosférico carrega consigo também o pneûma e o corpo consegue extrair este daquele; ou o ar é transformado em pneûma dentro do corpo, pelo processo da respiração. Sustenta a primeira interpretação a ideia de hágion pneûma, o sagrado sopro, ou seja, uma fonte universal de onde cada indivíduo retiraria o seu pneûma particular. Assim ele viria já pronto desta fonte universal, que algumas vezes é chamada de "éter". Os correspondentes termos latinos desses conceitos são mais familiares para nós. Vamos apresentá-los na sequência, dando a tradução tradicional: sôma é corpus $=$ corpo $($ sárx é caro $=$ carne); como já citado, pneûma é spiritus (em latim spirare é respirar) = espírito ou sopro; pneûma hágion é spiritus sanctus $=$ espírito santo; psykhé é anima = alma. Até este ponto de nossa especulação, o ser, o ánthropos (homo em latim) é entendido como pluridimensional, embora unitário. Ele tem uma dimensão corporal ou somática, outra pneumática e outra anímica (não empregaremos "dimensão espiritual”, nem “dimensão psíquica”, apesar do vínculo etimológico imediato, pois normalmente esses termos possuem uma significação própria que difere de nosso entendimento, como explicaremos mais adiante).

O pneûma vem, sobretudo, do ar respirado (algumas tradições dirão também que ele vem dos alimentos, da água e do sol), que adentra o corpo e nos pulmões é passado para o sangue. Desse modo, a expressão concreta do pneûma no sôma é o próprio sangue. Em outros termos, o sangue carrega o pneûma. Assim, onde há sangue há pneûma. Todavia, o sangue circula pelas veias e artérias, mas o pneûma é entendido, por diversas tradições, como algo que circula por canais e meridianos próprios. Não há clareza no pensamento grego sobre a circulação do pneûma, que não seja por veias e artérias (os respiradouros de Hipócrates, como veremos abaixo). Como o ar entra, oxigena o corpo e sai levando suas

\footnotetext{
$3 \sigma \hat{\omega} \mu \alpha$, que daí deriva, por exemplo, em português "somático". O termo não claramente se distingue de sárx $\sigma \alpha ́ \rho \xi$, traduzido normalmente como "carne".

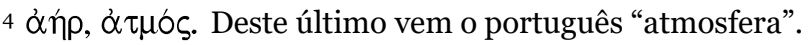

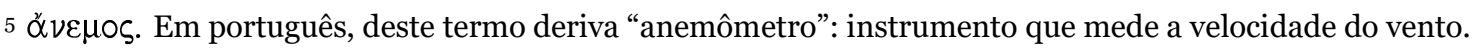


impurezas, algo talvez aconteça de semelhante com o pneûma: ele entra, vitaliza o corpo e sai também (levando algo?). Do ponto de vista da forma, se o pneûma circula por todo o corpo, ao final sua forma é idêntica ao do corpo. Diremos então que há um envoltório pneumático, que se situa na sua correspondente dimensão, ou seja, na dimensão pneumática ou vital. O termo "vital" é particularmente interessante, pois vita em latim traduz o grego bíos, como vimos na nota 2 acima.

O termo grego para cérebro é enképhalon, que designa algo que está dentro (em grego en) da cabeça, kephalé. Ambos derivam da raiz indo-europeia KER, cujo significado é alto, topo. Os equivalentes latinos guardam associação parecida: caput, cabeça; cerebrum, cérebro, isto é, o que a cabeça carrega. Isso parece querer dizer o quanto o homem antigo desconhecia o que seria o cérebro. Embora "saibamos" na modernidade que o pensar é cerebral, todavia é muito difícil ter uma evidência concreta e mais imediata dessa percepção, pois determinadas ideias e sensações nos abalam a ponto de causar uma dor de estômago, ou provocar palpitações, ou provocar suor, ou desarranjar o intestino, ou alterar a respiração, ou provocar rubor, ou induzir tensões musculares, ou tirar o sono, ou fazer perder o apetite - tudo isto ocorre no tronco! Onde entra o cérebro em todas as acima citadas reações corporais? Mesmo uma dor de cabeça nem sempre é sentida como algo no interior da cabeça. Toda essa realidade está espelhada no vocabulário antigo. Assim foi entendida a fonte do pensamento e das emoções em diversas partes ou órgãos do tronco: no coração, kardía; no fígado, hêpar; no diafragma, phrén; no peito ou nas entranhas, thymós ${ }^{6}$. Há vocábulos gerais que parecem abranger mais do que os órgãos nomeados; desses termos destaca-se noûs, que vamos traduzir como mente, ânimo, inteligência, pensamento, emoção, sentimento. O termo latino mens, mente, possui um equivalente grego, ménos: mente, que também significa impulso, força7.

Escolhendo didaticamente então dois vocábulos que possam sustentar a ideia aqui defendida de constituição do ser, pensamos em thymós para o envoltório emocional e noûs para o envoltório mental. Por que não seriam órgãos das emoções e dos pensamentos e sim envoltórios? Porque um órgão pressupõe alguma localização mais precisa, enquanto envoltório abrange a totalidade do ser. Recordando que aqui thymós não é entendido como o peito do

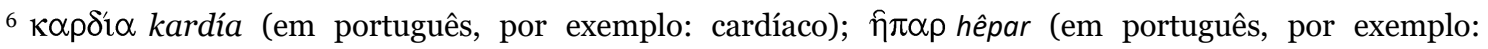

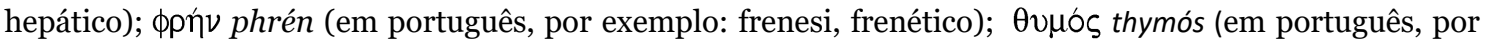
exemplo: timo, entusiasmo).

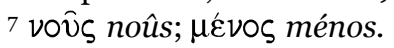


corpo, sôma, mas é algo que se situa numa dimensão que lhe é própria: a dimensão emocional. Do mesmo modo, noûs definiria um envoltório mental. Voltando a especular sobre esse grego arcaico, como não claramente ele distingue um pensamento de um sentimento, o termo noûs, o envoltório mental, abrangeria o envoltório emocional, thymós. Assim, o emocional está dentro do mental e é apenas para nossa facilidade de entendimento que os distinguimos. Uma dúvida persiste: há separação entre emoção, sentimento e pensamento?

Segundo a interpretação aqui proposta, sobre a psykhé, alma, não será possível desenvolver algum tipo de discurso lógico-argumentativo, pois essa dimensão ultrapassa a dimensão intelectual ou mental; é nela que estão as intuições, os insights, e coisas dessa natureza. Na tradição grega, como veremos mais abaixo, a alma vaga como uma sombra ou um sonho, depois da morte. Somente com vivências é que podemos ter alguma certeza do que seja a alma.

Em síntese, a constituição do ser:

\begin{tabular}{|l|l|}
\hline \multicolumn{1}{|c|}{ dimensão } & \multicolumn{1}{c|}{ envoltório } \\
\hline dimensão anímica & psykhé, anima, alma \\
\hline dimensão intelectual ou mental & $\begin{array}{l}\text { noûs, intelligentia, inteligência } \\
\text { e/ou } \\
\text { ménos, mens, mente }\end{array}$ \\
\hline dimensão emocional & thymós, animus, ânimo \\
\hline dimensão pneumática ou vital & pneûma, spiritus, sopro \\
\hline dimensão somática ou corporal & sôma, corpus, corpo \\
\hline
\end{tabular}

Embora, como comentado, o termo spiritus, espírito ou sopro, traduza com fidelidade pneûma, "dimensão espiritual" parece significar "dimensão anímica" e nunca "dimensão vital"; por esse motivo não o empregaremos. Da mesma dificuldade é o termo psykhé, alma; assim, "dimensão psíquica” não significa "dimensão anímica”, mas um composto das dimensões mental e emocional. Também não o empregaremos.

\section{NA TRADIÇÃO TEXTUAL: Rhée d' haîma kelainephés ${ }^{8}$}

Neste item, analisaremos algumas passagens épicas que podem ser interpretadas a partir da visão pluridimensional do ser, acima descrita. Na

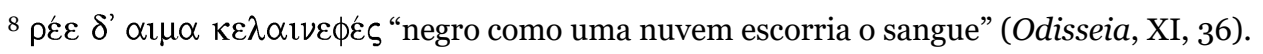


Odisseia de Homero, Canto XI, o personagem Odisseus (Ulisses para os latinos) vai ao extremo da terra, junto ao Oceano, rio que circunda o mundo conhecido, para falar com Tirésias, já morto. Nesse lugar sagrado, indicado pela deusa Circe, ele prepara o ambiente para a comunicação com os mortos. Faz um buraco e em torno dele deposita leite, mel, vinho doce, água e cevada branca. Em seguida, com votos e preces, invoca os mortos e degola os animais sobre o buraco. Assim que o sangue escorre pelo buraco, as almas (psykhé) dos mortos sobem da região subterrânea. Odisseus, com sua espada, mantém as almas afastadas, só permitindo que beba o sangue a alma com a qual deseja conversar. Resolvida a questão com Tirésias, ele passa a conversar com a alma de sua mãe. Na passagem seguinte (XI, v. 204-208), destaca-se um aspecto da natureza da alma, psykhé: ela vaga como uma sombra (skié) ou um sonho (óneiros), na região subterrânea. Destaca-se também o thymós (e/ou o phrén) como a sede das emoções. Leiamos o texto:
..., autàr egó g' éthelon phresì mermeríksas
metròs emês psykhèn heléein katatethneyíes.
trìs mèn ephorméthen, heléein té me thymòs anógei,
trìs dé moi ek kheirôn skiê eíkelon è kaì oneíroi
éptat'.9
... Em seguida eu quis, com ansiedade no phrén, abraçar a psykhé de minha mãe morta.
Três vezes tentei, o thymós conduziu-me a abraçá-la;
três vezes, como uma sombra ou um sonho, das mãos
ela voou ${ }^{10}$.

Em outra passagem (XI, v. 218-222), a mãe de Odisseus lhe explica o fenômeno "morte":

... all' haúte díke esti brotôn, hóte tís ke tháneisin:

ou gàr éti sárkas te kai ostéa înes ékhousin,

allà tà mén te puròs krateròn ménos aithoménoio

damnâi, epeí ke prôta lípei leúk'ostéa thymós,

psykhè d'eyt'óneiros apoptaméne pepótetai. ${ }^{11}$

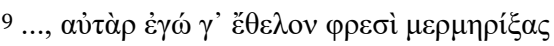

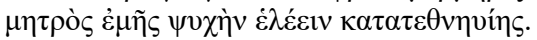

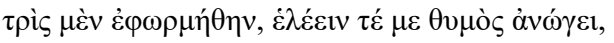

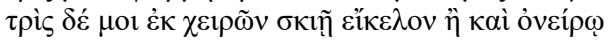
हैं $\pi \alpha \tau$ '.

10 No grego, psyché, alma, designa também a "borboleta".

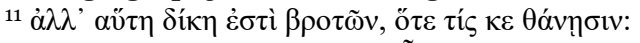

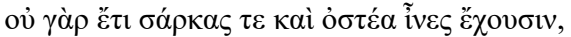

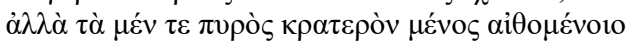

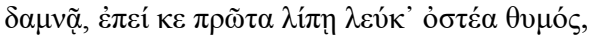

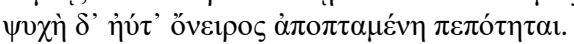


Mas esta é a lei dos mortais, quando alguém morre:

pois não mais os tendões seguram as carnes e os ossos, mas a poderosa mente do ardente fogo

os consome, primeiro o thymós deixa os brancos ossos,

e a psykhé, pairando fora como um sonho, voa.

Observamos em destaque a palavra sárx, traduzida normalmente como "carne". Nem sempre o termo se distingue de sôma, corpo. Parece ser a descrição de uma cremação. Ao fogo é atribuída também uma mente, ménos, que aqui pode ser entendida como uma força. Importante notar na passagem: quando alguém morre, desaparece a sua vitalidade, não há o elemento que mantém os órgãos, tecidos, ossos, etc., em união e funcionamento. Este elemento é o pneûma, não citado no trecho. Queima-se o sôma, dissolve-se o pneûma, mas parece que sobrevive o thymós. A alma, psykhé, seguirá voando para o seu destino, a região subterrânea. "O thymós deixa os brancos ossos”, em nossa interpretação, significa que deixa o corpo, pois não vemos sustentação para supor que a sede do thymós fosse os ossos. É no tronco o lugar onde normalmente se localiza a sede das emoções. Por ali, como vimos, concretamente se percebe o coração acelerar, a respiração se alterar, o estômago doer, o intestino se desarranjar diante de emoções fortes. Essas imagens expressam uma ideia sem definição clara. Defendemos ser o thymós um envoltório emocional, localizado na totalidade do ser, mas situado numa dimensão emocional, portanto sem localização no corpo. Traduziríamos o trecho acima do seguinte modo: “o envoltório emocional deixa o envoltório somático, e, junto com o envoltório anímico, vai embora”.

Como uma alma, psykhé, poderia se manifestar e estabelecer relações com Odisseus, se ela não mais possui sôma e pneûma, ou seja, um corpo vivo? As almas bebem o sangue dos animais sacrificados, ou, melhor dizendo, absorvem o pneûma dos animais, que escorre junto com o sangue. É como se a alma moldasse, nessa massa de pneûma do animal, um pseudocorpo, ou, melhor ainda, moldasse um envoltório pneumático e, através dele, conseguisse se manifestar, como fazia em vida, conversando, refletindo e se emocionando. Se o thymós acompanha a psykhé no mundo subterrâneo, aceito por hipótese, nesse episódio temos então um fantasma, uma aparição, um ser sem o sôma, mas com todos os demais elementos, ainda que o pneûma seja provisório. 


\section{APONTAMENTOS SOBRE O PENSAMENTO HIPOCRÁTICO}

A obra de Hipócrates ( 460-370 a.C.) é vasta, constituída por cerca de setenta livros, o chamado Corpus Hippocraticum. Nossa abordagem se limitará a três obras: Sobre a doença sagrada (Perì hierês noúsou), Sobre a natureza do homem (Perì physios anthrópou) e Aforismos (Aphorismoí). Nosso esforço é compreender como Hipócrates entende a constituição do ser, ou melhor, como reinterpreta a visão multidimensional, que é em grande parte intuitiva, para uma abordagem palpável ou concretamente observável.

Principia a obra Sobre a doença sagrada, com a afirmação de Hipócrates de não haver nela nada de sagrado, mas que se trata de uma doença como as demais. Sob o rótulo de doença sagrada se incluíam epilepsia e convulsões. Segundo nossa visão, todas as doenças que alteram o estado de consciência foram entendidas como sagradas. O termo "sagrado" que lhe segue se justifica pelo seguinte: o transe é uma alteração do estado de consciência, no qual se supõe que uma divindade se manifeste. Uma convulsão "imita" o transe. Aparentemente são iguais, todavia não se percebe a presença da divindade, ou seja, trata-se mesmo de uma doença.

Segundo explica Hipócrates, os magos, mágoi ${ }^{12}$, ao tratarem da doença sagrada "aplicam purificações, encantamentos e diversas prescrições"13, como interdição de determinados alimentos, de certas roupas e de alguns hábitos ("não manter pé sobre pé nem mão sobre mão"14). No mesmo texto, mais abaixo, ele continua a reprimenda ao embusteiro, "aquele que faz purgações e magia"15. Entre as maravilhas que um mago poderia fazer estão, por exemplo, "baixar a lua e ocultar o sol"16. Defende finalmente seu ponto de vista: "mas de fato o cérebro é o causador desta doença"17, e passa a descrever as veias e os órgãos a elas ligados. Explica ainda que "através destas veias também recolhemos muito do pneûma, pois essas são respiradouros (anapnoaí) do nosso corpo, ao levar o ar até elas, e ao resto do corpo [...]"18. E ainda acrescenta: "assim o pneûma não se estanca, mas escorre para cima e para

\footnotetext{
$12 \mu \alpha ́ \gamma о 1$.

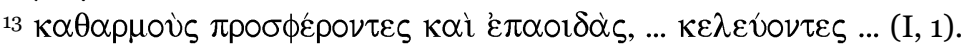

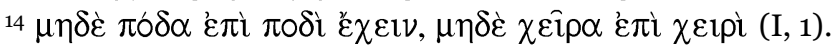

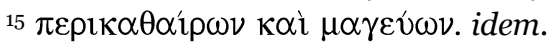

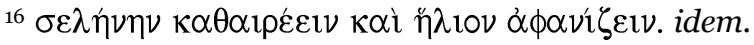

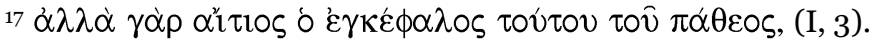

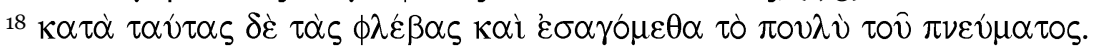

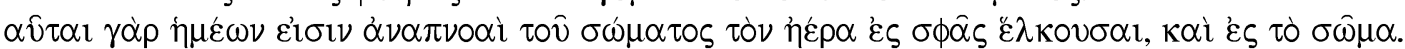

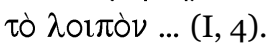


baixo"19. Será, portanto, explicada a doença sagrada através da circulação interna, no corpo, do ar, do pneûma e dos quatro humores (fleuma, sangue, bílis amarela, bílis negra), e a isso se associa a circulação externa dos ventos (Noto, Bóreas, etc.).

Todo o parágrafo quatorze da referida obra é dedicado ao cérebro. É dele que provêm "nossos prazeres, as alegrias, risos e brincadeiras [...], e sofrimentos, aflições, desgostos e prantos"2o. É por meio dele que "pensamos, compreendemos, vemos, ouvimos e conhecemos [...]"21.

Na obra Sobre a natureza do homem, Hipócrates desenvolve a teoria dos quatro humores e sua relação com saúde/doença: "o corpo do homem tem em si sangue, fleuma, bílis amarela e negra, e essa é a natureza (physis) do corpo dele, e por meio dela tem doença e tem saúde" ${ }^{22}$. Comenta ainda o erro daqueles que "vendo os homens sendo degolados e o sangue escorrendo do corpo, chamam ser isto a alma (psykhé) do homem"23.

Finalmente, nos Aforismos, destacamos os seguintes:

2.6 Aqueles que, sofrendo um mal no corpo, em geral não percebem os males, nestes o conhecimento (gnóme) está doente ${ }^{24}$.

5.63 [...] Ou pela fraqueza do corpo, o pneûma se dissipa, não impulsiona o esperma $[\ldots]^{25}$.

6.23 Quando o medo ou a tristeza se prolongam por muito tempo, configura-se um estado melancólico ${ }^{26}$.

Faremos na sequência uma síntese do pensamento hipocrático, a partir das três obras consultadas. Repetimos, trata-se de apontamentos, visto que a grandeza do corpus hippocraticum não foi toda explorada, apesar de as obras escolhidas serem muito representativas do autor.

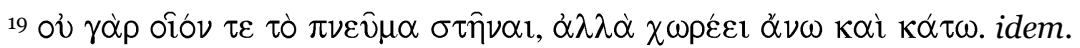

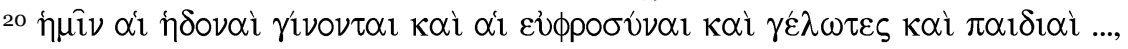

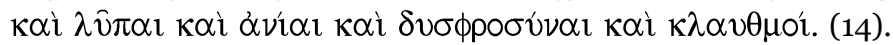

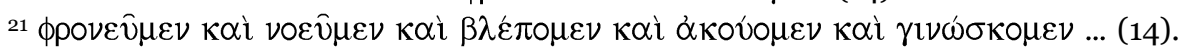

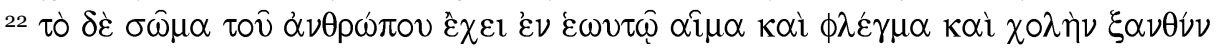

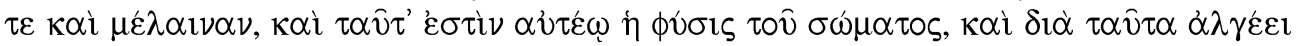

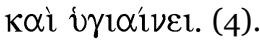

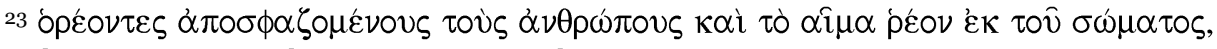

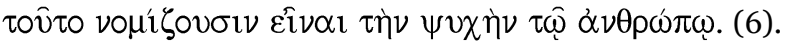

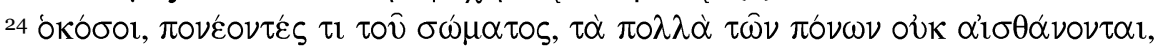

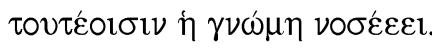

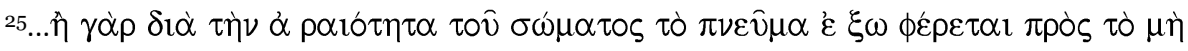

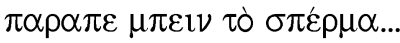

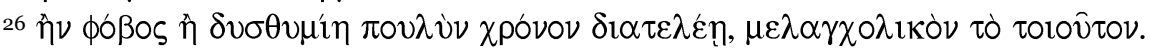


Parece, portanto, materialista a concepção sobre a constituição do ser, em Hipócrates. Sendo pensamentos, sentimentos e emoções oriundos do cérebro, não há lugar para a psykhé (envoltório anímico), nem para o noûs (envoltório mental), nem para o thymós (envoltório emocional), como entidades, de certo modo, autônomas. Não é pela desarmonia entre os envoltórios que será caracterizada a doença, mas apenas pela desarmonia dos fluidos próprios do corpo, sôma. Continua, todavia, em Hipócrates, a aceitação de um elemento vital para manter a vida; este provém do ar e circula junto com o sangue, mas não é o sangue, é outra coisa. Supomos que alguma materialidade ele devesse aceitar para o pneûma, de modo que o mesmo continua a fazer parte de seu sistema materialista.

Um resumo da terapêutica hipocrática é dado por Ribeiro Jr.:

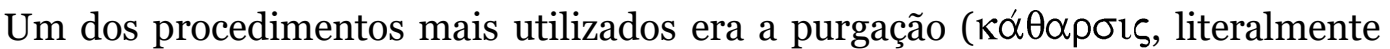
"purificação"), a eliminação dos humores nocivos, obtida através da administração de alimentos e de medicamentos laxantes, eméticos, expectorantes e esternutatórios, e de clisteres, insuflações, supositórios, sangrias, incisões para a drenagem de pus e até mesmo trepanações cranianas. [...] Os humores nocivos acumulados tinham que ser mobilizados, o que era obtido pela aplicação de ventosas, fomentações, fumigações (inaladas ou por via vaginal) e cauterizações. Preconizava-se invariavelmente uma dieta $\left(\delta^{\prime} \iota_{\alpha} \imath \tau \alpha\right)$, que compreendia alterações em todo o estilo de vida. (RIBEIRO JR., 2005, p. 207-208).

A dieta hipocrática também contém prescrições. Certamente não semelhantes àquelas acima citadas dos magos. $\mathrm{O}$ que parece ser então o grande diferencial entre a medicina arcaica, que concebe o ser pluridimensional, e a medicina hipocrática, que concebe o ser constituído de sôma e pneûma, com destaque para o cérebro, é de fato o encantamento. Os demais elementos são em certa medida comuns.

Vejamos na sequência uma passagem de texto, em que o encantamento se aplica.

\section{FÓRMULA DE ENCANTAMENTO}

Na Odisséia, 19, v. 455-458, a ama Euricleia, ao lavar os pés de Odisseus, disfarçado, o reconhece por causa de uma cicatriz. Neste momento, o narrador descreve os acontecimentos que provocaram o ferimento. Odisseus, quando jovem, visitara seu avô materno, Autólico. Lá, junto ao monte Parnaso, vai com seus companheiros à caça. Odisseus é atacado por um javali. Ao mesmo tempo em que o mata, é ferido na perna pela presa do animal. São descritos dois 
procedimentos para socorrer o herói: primeiro atam o ferimento e, segundo, entoam um canto mágico, epaoidé ${ }^{27}$ :

Os filhos queridos de Autólico o auxiliaram; a ferida do irrepreensível Odisseus, semelhante a um deus, ataram habilmente, e com um encantamento o sangue negro estancaram ${ }^{28}$.

O grego epaiodé (encantamento) é uma variante do termo ode (canto). A fórmula mágica de encantamento tem seus equivalentes em outras culturas: na Índia, trata-se do mantra, em Roma chama-se carmen. $\mathrm{O}$ encantamento consiste em uma ou mais palavras, cujo significado muitas vezes é incompreensível, que deve ser entoado segundo um modo aprendido da tradição, ou seja, aprende-se como fazê-lo da viva voz de um mestre. Há uma maneira "correta" de pronunciá-lo, sob o risco de não ter validade ou provocar efeitos indesejáveis. O encantamento, muitas vezes, é acompanhado de algum rito (POSSEBON, 2008 b, p. 58-59).

Se aceitarmos que a atadura feita pelos companheiros de Odisseus atuou sobre o sôma, estancando fisicamente a saída do sangue, podemos então supor que o encantamento teria agido sobre os demais envoltórios, para o esforço de restabelecer sua saúde. Se isto for aceitável, reconhecemos que a medicina arcaica dos magos oferecia soluções, como estranhas prescrições e encantos, para a saúde integral do ser, numa visão que modernamente chamaremos de holística. Baseava-se no poder da palavra; em grego arcaico, usava-se para este conceito os termos mythos, lógos e épos ${ }^{29}$.

\section{CONCLUSÕES}

A espiritualidade grega arcaica é a maneira como este homem primitivo se colocava no mundo, entendendo-se pluridimensional, ou seja, sendo um ser único, um ánthropos, mas revestido de envoltórios sucessivos que abrigam a sua essência, a alma, psykhé. A plenitude do ser depende da harmonia entre suas partes constituintes. Doença é a desarmonia e saúde o seu oposto, o perfeito equilíbrio entre os envoltórios. O termo "espiritualidade" contém do

\footnotetext{
27 '̇ $\pi \alpha \circ \imath \delta \dot{\eta}$.

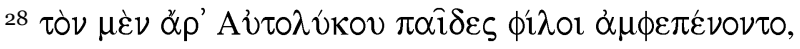

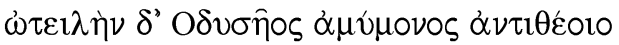

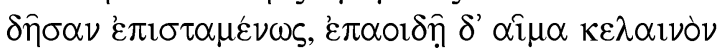

$\varepsilon \approx \chi \varepsilon \theta \circ \nu$.

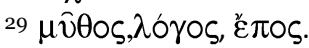


ponto de vista etimológico uma restrição, mas somente desse ponto de vista, porque espírito, ou pneûma, é apenas um dos constituintes do ser. A busca pela totalidade do ser melhor seria caracterizada por um termo como "psiquidade". Falamos, todavia, muito pouco da psykhé propriamente dita. E não poderia ser diferente, porque o domínio da alma transcende o domínio da razão. Esta se situa no envoltório mental, o noûs; aquela está além, ela de fato voa como a borboleta, na concreta visão grega da realidade. Qualquer aproximação à alma depende de vivências, como meditações, experiências extáticas, insights, intuições, e coisas dessa natureza.

Concluímos, citando alguns sistemas de constituição do ser, comparáveis ao dos gregos arcaicos, sem o aprofundamento das discussões. No Cristianismo Primitivo: alma (ou espírito) e corpo (em poucas passagens como Hebreus 4,12 e 1 Tessalonissenses, 5, 23: alma, espírito e corpo); no Espiritismo: espírito, perispírito e corpo (o equivalente ao pneûma é dito fluido vital); na Teosofia: corpo denso, duplo etérico, corpo astral, corpo mental, corpo causal e alma (para detalhes vide Leadbeater, 2013, s/d, 2009); no Tantra30: anna-mayakosha, prana-maya-kosha, mano-maya-kosha, vijnana-maya-kosha, anandamaya-kosha e a essência (purusha, atman, aham); na Psicossomática: corpo e psique31.

Pretendemos, em síntese, nesse breve ensaio, mostrar que o entendimento de uma existência pluridimensional do ser estava já na Grécia arcaica, ainda que rudimentarmente desenvolvida.

\section{REFERÊNCIAS}

ALEXANDER, Franz. Medicina Psicossomática: princípios e aplicações. Porto Alegre: Artes Médicas, 1989.

BAILLY, A. Dictionnaire Grec-Français. Rédigé avec le concours de E. Egger. Paris: Hachette, 1950.

BIASE, Francisco de. O homem holístico: a unidade mente-natureza. Petrópolis: Vozes, 2010.

\footnotetext{
30 "A primeira e mais substancial é chamada anna-maya-kosha, 'o envoltório (kosha) feito (maya) de alimento (anna)' que, logicamente, é o corpo denso e seu mundo de matéria densa [...] O segundo envoltório, prana-maya-kosha, 'o envoltório feito de forças vitais (prana), e o terceiro, mano-maya-kosha, 'o envoltório feito de mente [e sentidos] (manas)', junto com o quarto, vijnana-maya-kosha, 'o envoltório feito de entendimento [compreensão] (vijnana)', compõem o corpo sutil, que corresponde ao plano da consciência durante os sonhos; ao passo que o quinto, ananda-maya-kosha, 'o envoltório feito de beatitude (ananda)', que corresponde ao plano do sono profundo [...], é o que se conhece com o nome de corpo causal" (ZIMMER, 1986, p. 294).

31 “[...] os fenômenos somáticos e psicológicos ocorrem no mesmo organismo e são meramente dois aspectos do mesmo processo. No organismo vivo, certos processos fisiológicos são percebidos subjetivamente como sentimentos, ideias e pulsões.” (ALEXANDER, 1989, p. 46).
} 
BLOISE, Paulo. Medicina integrativa: corpo, mente e espiritualidade. In: BLOISE, Paulo (org.). Saúde Integral: a medicina do corpo, da mente e o papel da espiritualidade. São Paulo: SENAC, 2011.

BOTSARIS, Alexandros. A ciência média - um modelo obsoleto? In: PELIZZOLI, Marcelo (org.). Saúde em novo paradigma: alternativas ao modelo da doença. Recife: Editora Universitária da UFPE, 2011.

CUNLIFFE, Richard John. A lexicon of the homeric dialect. University of Oklahoma Press, 1963.

DODDS, E.R. Os gregos e o irracional. São Paulo: Gradiva, 1988.

FERREIRA, Aurino Lima. Espiritualidade e educação: um diálogo sobre quão reto é o caminho da formação humana. In: ROHR, Ferdinand (org.). Diálogos em educação e espiritualidade. Recife: Editora Universitária da UFPE, 2012.

HOMERO. Odisseia. Tradução de Jaime Bruna. São Paulo: Cultrix, sd.

IPPOCRATE. Aforismi e Giuramento. Traduzione de Marco. T. Malato. Milano: Newton, 1994.

LEADBEATER, Charles W. Clarividência. Brasília: Teosófica, 2013.

O homem visível e o invisível: um estudo das variações da aura dos diferentes tipos de indivíduos. São Paulo: Pensamento, s.d.

Os Chakras. Limeira: Conhecimento, 2009.

LIDDELL, Henry George; SCOTT, Robert. Dizionario Illustrato Greco-Italiano. Edizione adattata e aggiornata a cura de Q. Cataudella, M. Manfredi e F. de Benedetto. Firenze: Le Monnier, 1975.

OMERO. Odissea. Tradução de Aurelio Privitera. Arnoldo Mondadori Editore, 1991.

POSSEBON, Fabricio. A inscrição execratória de Pella. In: Revista Interações Cultura e Comunidade, volume 3, número 3, p. 33-44, 2008 a.

A dramaturgia trágica sempre foi racionalista (Prefácio). In: LUNA, Sandra.

Drama Social, Tragédia Moderna: ensaios em teoria e crítica. João Pessoa:

Editora Universitária da UFPB, 2012.

.Tò Thaumastón: o maravilhoso: introdução ao pensamento grego arcaico. João Pessoa: Editora Universitária da UFPB / Zarinha Centro de Cultura, $2008 \mathrm{~b}$.

ROHR, Ferdinand. Espiritualidade e Educação. In: ROHR, Ferdinand (org.) Diálogos em educação e espiritualidade. Recife: Editora Universitária da UFPE, 2012.

RIBEIRO JR., Wilson; CAIRUS, Henrique. Textos Hipocráticos: o doente, o médico e a doença. Rio de Janeiro: Fiocruz, 2005. 
SAMPAIO, Dilaine Soares; POSSEBON, Fabricio. Pneûma, Amén, Emi, Axé: aproximações possíveis? In: SAMPAIO, Dilaine Soares; POSSEBON, Fabricio (orgs.). Epístola aos Romanos. João Pessoa: Editora Universitária da UFPB, 2015, p. 105118.

ZIMMER, Heinrich. Filosofias da Índia. São Paulo: Palas Athena, 1986.

Recebido em 19/o9/2016 Aprovado em 06/11/2016 